\title{
Adoção de inovação: internet das coisas para melhoria de desempenho de sustentabilidade na Klabin
}

Miriam Christi Midori Oishi Nemoto

Coordenadora do Curso de Administração da UNIFESP - Universidade Federal de São Paulo. Doutora em Administração de Empresas pela Faculdade de Administração, Economia e Contabilidade da USP - Universidade de São Paulo, com Doutorado Sanduíche na Southern Illinois University. Bacharel e Licenciada em Química Industrial pela UFPR - Universidade Federal do Paraná. Especialista em Engenharia de Produção pela UFPR. Mestre em Administração de Empresas pela Fundação de Ensino e Comércio Álvares Penteado, São Paulo, Brasil miriamoishi@yahoo.com.br

Gabriel Zago Vieira Santos

Pesquisador da Universidade Federal de São Paulo (UNIFESP), pela qual é graduado em Administração. Atuou na área de gestão corporativa de sustentabilidade e comunicação da Klabin S/A. Foi bolsista pesquisador do CNPq; voluntário pesquisador PIBEX-UNIFESP; integrou a coordenação de várias frentes no Programa de Gestão e Educação para a Sustentabilidade (GES), São Paulo, Brasil

gabrielzvs@gmail.com

Luis Hernan Contreras Pinochet

Doutor pela Escola de Administração de Empresas de São Paulo da Fundação Getúlio Vargas (FGV-EAESP). Mestre em Administração pela Pontifícia Universidade Católica do Paraná (PUC-PR). Especialista em Tecnologia da Informação e Comunicação pela FAE Centro Universitário (Paraná). Bacharel em Informática pela Universidade Positivo (Paraná). Professor de Administração da EPPEN - Escola Paulista de Política, Economia e Negócios da Unifesp Universidade Federal de São Paulo, São Paulo, Brasil

luishernan@terra.com.br

Editor Científico: José Edson Lara
Organização Comitê Científico
Double Blind Review pelo SEER/OJS
Recebido em 06.09.2017
Aprovado em 06.11.2017

\footnotetext{
(c) (i) (8)

Este trabalho foi licenciado com uma Licença Creative Commons - Atribuição - Não Comercial 3.0 Brasil
} 


\title{
Resumo
}

A partir dos temas contemporâneos sobre inovação, sustentabilidade e Internet das Coisas, foi realizado um estudo de caso que objetivou estudar como a adoção da inovação tecnológica pode auxiliar a melhoria do desempenho de sustentabilidade na empresa Klabin S.A. de papel e celulose. A pesquisa, de abordagem qualitativa, fez uso de um questionário que foi aplicado a um grupo de gestores da Klabin, de áreas relacionadas a pesquisa e desenvolvimento, tecnologia da informação e sustentabilidade, para verificar a importância dada à inovação e ao conhecimento desses gestores sobre a tecnologia da Internet das Coisas. As entrevistas foram analisadas a partir dos softwares NVivo e Sentiment Analyzer. Como resultado, observou-se que a exigência por parte dos clientes é o principal fator que influencia a adoção de novas tecnologias na Klabin, e a companhia se coloca como fastfollower quando se refere a inovações, não sendo pioneira, e que é possível inovações tecnológicas melhorarem o desempenho de sustentabilidade da empresa.

Palavras-chave: Adoção de inovação; Papel e celulose; Sustentabilidade.

\section{Adoption of innovation: internet of things to improve sustainability performance at Klabin}

\begin{abstract}
Based on an analysis of the available scientific literature on innovation, sustainability and Internet of things, a case study was carried out, whose objective was to study how the adoption of technological innovation can help to improve the sustainability performance of Klabin S.A. pulp and paper company. The qualitative research used a questionnaire that was applied to a group of Klabin managers in areas related to research and development, information technology and sustainability, to verify the importance given to innovation and the knowledge of these managers about the Internet of Things technology. The interviews were analyzed using NVivo and Sentiment Analyzer software. Results show that customer demand is the main factor that influences the adoption of new technologies in Klabin and the company places itself as fast-follower when it comes to innovations, not pioneering; and that it is possible for technological innovations to improve the company's sustainability performance.
\end{abstract}

Key-words: Adoption of innovation; Pulp and paper; Sustainability.

\section{Adopción de innovación: internet de las cosas para mejorar el desempeño de la sostenibilidad en Klabin}

\section{Resumen}

A partir de los temas contemporáneos sobre innovación, sostenibilidad y la Internet de las Cosas, se realizó un estudio de caso, que tuvo como objetivo estudiar cómo la adopción de la innovación tecnológica puede auxiliar en la mejora del desempeño de sostenibilidad en la empresa Klabin S.A. de papel y celulosa. La investigación, de enfoque cualitativo, hizo uso de un cuestionario que fue aplicado a un grupo de 
gestores de Klabin, de áreas relacionadas a investigación y desarrollo, tecnología de la información y sostenibilidad, para verificar la importancia dada a la innovación y el conocimiento de esos gestores sobre la tecnología de Internet de las Cosas. Las entrevistas fueron analizadas a partir de los softwares NVivo y Sentiment Analyzer. Como resultado, se observó que la exigencia por parte de los clientes es el principal factor que influye en la adopción de nuevas tecnologías en Klabin y la compañía se coloca como fast-follower cuando se refiere a innovaciones, no siendo pionera; y que es posible que las innovaciones tecnológicas mejoren el rendimiento de la sostenibilidad de la empresa.

Palabras clave: Adopción de innovación; Papel y celulosa; Sostenibilidad.

\section{Introdução}

Alguns ambientes organizacionais são mais propícios à inovação que outros em função da crescente competitividade, o que permite uma reação rápida diante das contingências do ambiente externo, assim como a mudanças nos hábitos dos consumidores, sistema político-legal, fornecedores, entre outros (Damanpour \& Schneider, 2006; Egeraat \& Kogler, 2013; Souza \& Bruno-Faria, 2013).

Nesse sentido, o desenvolvimento de produtos inovadores pode reunir vantagens competitivas singulares, favorecendo, assim, a diferenciação da empresa e influenciando seu ambiente com suas estratégias. A inovação também pode ocorrer em processos operacionais, como a forma com que novos produtos e serviços são entregues aos consumidores (Souza \& Bruno-Faria, 2013; Lencioni, 2015; Timilsina, Kotani \& Kamijo, 2017).

As soluções ecologicamente corretas aumentarão a competitividade e fortalecerão as empresas a se transformarem. Nesse cenário, surge a ecoinovação, que se remete a todos as formas de inovação, tecnológicas ou não, que criam oportunidades de negócio e, ao mesmo tempo, beneficiam o ambiente e sua relação com a sustentabilidade (Maçaneiro \& Cunha, 2015).

Diante disso, a sustentabilidade diz respeito a mudanças que, frequentemente, são relacionadas a iniciativas de redução de custos com recursos não renováveis e ao aproveitamento de materiais e produtos reciclados (Waring \& Tremblay, 2016). Portanto, mudança é uma das palavras-chave da inovação. Mudanças na forma de pensar, agir, quebra de paradigmas, gestão e criação. 
Mudanças que deixam seu estado utópico para fazer parte da busca pela construção da ordem a partir do caos (Maçaneiro \& Cunha, 2015).

Em tal contexto, o conceito tecnológico da Internet das Coisas ou Internet of Things emerge como instrumento capaz de relacionar assuntos do ambiente à troca de informações por meio da tecnologia móvel, envolvendo a colaboração e integração no ambiente pelo meio digital (Paes, 2014). Seu potencial permite também que objetos do cotidiano sejam programados e funcionem como propulsores de inovação no ambiente digital (Lindqvist \& Neumann, 2017).

O estado da arte desta pesquisa é observar a Internet das Coisas como um elemento tecnológico que tem implicações na sustentabilidade e inovação no processo produtivo. Sendo assim, o presente estudo tem como objetivo geral entender a adoção da inovação tecnológica no auxílio da melhoria do desempenho de sustentabilidade na empresa Klabin S.A. de papel e celulose.

O artigo possui a seguinte estrutura: introdução, fundamentação teórica (que fornece base conceitual do tema), metodologia, análise dos resultados e, por fim, as conclusões e recomendações gerenciais.

\section{Referencial Teórico}

Nesta seção, são apresentadas as abordagens teóricas que sustentaram esta pesquisa, subdividas em: adoção de inovação e suas características; sustentabilidade e ecoinovação; e Internet das Coisas para melhoria do desempenho de sustentabilidade.

\subsection{Adoção de inovação e suas características}

Inovação é um conceito amplo e de diferentes abordagens, que muitas vezes pode ser confundido com criatividade ou invenção. Não existe uma teoria unificada sobre o tema. Há explicações parciais em diversas áreas do conhecimento: economia, sociologia, estudos organizacionais, tecnologia, política e psicologia, que juntas se complementam. A utilidade de cada teoria dependerá das questões que se deseja particularmente estudar (Neto \& Longo, 2001).

Além disso, inovar é recriar modelos de negócio e construir mercados totalmente novos, que complementam as necessidades humanas não atendidas, 
selecionando e executando as ideias certas e trazendo-as em tempo recorde para o mercado. Qualquer teoria da inovação precisa explicar um fenômeno empírico e que assume várias formas, além de englobar sua complexidade, dinamismo e incerteza. A própria inovação resulta de muitas partes divergentes e não estabelecidas por completo.

Nesse sentido, observa-se que a inovação tecnológica diz respeito à adoção de novas tecnologias, como dispositivos e máquinas, que permitem aumentar a competitividade da companhia (Martins, 2015). Nas organizações, dentro de um processo de aceleração, há uma relação direta entre os esforços de P\&D e a inovação tecnológica (Neto \& Longo, 2001; Raeder, 2016).

Tal aceleração não diz respeito apenas ao fluxo de surgimento de novos produtos, mas também à crescente disposição de as pessoas (envolvidas no processo) abraçarem esses produtos (Brooke, 2016).

A responsabilidade da inovação nas empresas, há alguns anos, era exclusiva do departamento de $P \& D$, pois quase todas as inovações eram tecnológicas, porém há uma tendência de que tais responsabilidades sejam compartilhadas com outros departamentos envolvidos no processo (Neto \& Longo, 2001; Brooke, 2016).

A Tabela 1 apresenta os principais fatores influenciadores na adoção de inovação nas empresas: característica organizacional, influência dos colaboradores, modelo de gestão e perfil do gestor.

\section{Tabela 1}

Fatores influenciadores na adoção de inovação nas empresas

\begin{tabular}{|c|c|c|c|}
\hline Fator & Variáveis & Fatores influenciadores & Autores \\
\hline \multirow{5}{*}{$\begin{array}{l}\text { Característica } \\
\text { Organizacional }\end{array}$} & Complexidade & $\begin{array}{l}\text { Especialidade ocupacional do } \\
\text { indivíduo que irá utilizar a inovação } \\
\text { e disponibilidade de treinamento } \\
\text { profissional. }\end{array}$ & \multirow{3}{*}{$\begin{array}{l}\text { Kim (1980); Kimberley e } \\
\text { Evanisko (1981); } \\
\text { Damanpour (1991). }\end{array}$} \\
\hline & Formalização & $\begin{array}{l}\text { Resistência por parte do } \\
\text { colaborador que executará o novo } \\
\text { trabalho. }\end{array}$ & \\
\hline & Centralização & $\begin{array}{l}\text { Hierarquia de autoridade } \\
\text { participação na tomada de decisão } \\
\text { de inovação. }\end{array}$ & \\
\hline & Porte da empresa & $\begin{array}{l}\text { A relação entre o porte da empresa } \\
\text { e a velocidade de inovação. }\end{array}$ & $\begin{array}{l}\text { Kimberley e Evanisko } \\
\text { (1981); Dewar e Dutton } \\
\text { (1986); Damanpour } \\
\text { (1992); Stock et al. } \\
\text { (1996); Subramanian e } \\
\text { Nilakanta (1996) e } \\
\text { Kessler e Chakrabarti } \\
\text { (1996). }\end{array}$ \\
\hline & Nível de centralização & A tomada de decisão pode ser & Kim (1980); Damanpour \\
\hline
\end{tabular}


(conclusão)

\begin{tabular}{|c|c|c|c|}
\hline \multirow[t]{2}{*}{$\begin{array}{l}\text { Influência dos } \\
\text { Colaboradores }\end{array}$} & Cultura & $\begin{array}{l}\text { A cultura pode favorecer ou } \\
\text { dificultar a adoção da inovação, } \\
\text { dependendo da experiência do } \\
\text { indivíduo. }\end{array}$ & $\begin{array}{l}\text { Zmud (1982); Dunphy } \\
\text { et al. (1995) e Rigby } \\
\text { (1997). }\end{array}$ \\
\hline & Competência & $\begin{array}{l}\text { Conhecimento para utilização } \\
\text { da nova tecnologia. }\end{array}$ & $\begin{array}{l}\text { Johannessen et al. e } \\
\text { Dunphy et al. (1995). }\end{array}$ \\
\hline \multirow{3}{*}{$\begin{array}{l}\text { Modelo de } \\
\text { Gestão }\end{array}$} & $\begin{array}{l}\text { Difusão do } \\
\text { conhecimento }\end{array}$ & $\begin{array}{l}\text { O "compartilhamento" do } \\
\text { conhecimento entre os } \\
\text { indivíduos favorece a inovação. }\end{array}$ & Fiol (1996). \\
\hline & $\begin{array}{l}\text { Construção do } \\
\text { conhecimento }\end{array}$ & $\begin{array}{l}\text { O modo como o conhecimento é } \\
\text { gerado na empresa. }\end{array}$ & Venkatraman (1991). \\
\hline & Nível de recursos & $\begin{array}{llr}\text { Critérios } & \text { utilizados pelos } \\
\text { gestores para alocação de } & \text { de } \\
\text { recursos para projetos de } \\
\text { inovação tecnológica. }\end{array}$ & $\begin{array}{l}\text { Dutton e Duncan } \\
\text { (1987). }\end{array}$ \\
\hline \multirow[t]{2}{*}{$\begin{array}{l}\text { Perfil do } \\
\text { Gestor }\end{array}$} & $\begin{array}{c}\text { Experiência } \\
\text { profissional na } \\
\text { empresa atual e em } \\
\text { outras; formação } \\
\text { educacional e } \\
\text { proporção de gestores } \\
\text { com experiência } \\
\text { técnica. }\end{array}$ & $\begin{array}{l}\text { Influência do gestor na tomada } \\
\text { da decisão de adoção da } \\
\text { inovação. }\end{array}$ & $\begin{array}{l}\text { Schoemecker, } \\
\text { Daellenbach e } \\
\text { McCarthy (1996). }\end{array}$ \\
\hline & $\begin{array}{l}\text { Idade; especialização; } \\
\text { experiências passadas } \\
\text { com a tomada de } \\
\text { decisão em adoção de } \\
\text { inovação, iniciativa em } \\
\text { adotar. }\end{array}$ & $\begin{array}{l}\text { Influência do gestor na tomada } \\
\text { da decisão de adoção da } \\
\text { inovação. }\end{array}$ & $\begin{array}{l}\text { Tabak e Barr (1996) e } \\
\text { Damanpour e } \\
\text { Schneider (2006). }\end{array}$ \\
\hline
\end{tabular}

Fonte: Nemoto, M. (2009). Inovação Tecnológica: Um estudo exploratório de adoção do RFID (identificação por radiofrequência) e redes de inovação internacional. (Tese de Doutorado em Administração. Universidade de São Paulo, São Paulo, SP, Brasil).

A Tabela 2 mostra as características de inovação nas empresas (orientação externa e transparência em processos de inovação, cooperação entre departamentos, aprendizagem e adaptação, liderança, autonomia e possibilidade de experimentação e direcionador de resultado) e traz as definições associadas a cada uma delas.

\section{Tabela 2}

Características de inovação nas empresas

\begin{tabular}{l|ll}
\hline \multicolumn{1}{c|}{ Característica } & \multicolumn{1}{c}{ Definição } \\
\hline $\begin{array}{l}\text { Orientação externa e transparência em } \\
\text { processos de inovação }\end{array}$ & $\begin{array}{l}\text { A companhia foca em diferenciação e } \\
\text { competitividade com outras organizações. }\end{array}$ \\
\hline Cooperação entre departamentos & $\begin{array}{l}\text { A companhia promove sinergia e facilita a } \\
\text { comunicação entre diferentes departamentos. }\end{array}$ \\
\hline Aprendizagem e adaptação & $\begin{array}{l}\text { A companhia procura entender o ambiente de } \\
\text { competitividade de outras organizações e se } \\
\text { adapta às realidades observadas. }\end{array}$ \\
\hline
\end{tabular}




Miriam Christi Midori Oishi Nemoto, Gabriel Zago Vieira Santos e Luis
Hernan Contreras Pinochet

Fonte: Rosa, L., Kneipp, J.; Bichueti, R.; Gomes, C.; Zamberlan, J. (2013). The Innovation Process and the Development of a Sustainability Strategy. Latin American Business Review, p. 289-308.

Sendo assim, percebem-se fatores que influenciam empresas a adotarem inovações e também as características de inovação nas empresas. O perfil do gestor, por exemplo, pode ter alta influência na adoção de inovações por conta de sua experiência profissional, formação, idade, entre outros. O porte da empresa também está relacionado à velocidade da inovação, como apresentado na Tabela 2.

$\mathrm{Na}$ discussão sobre tecnologia, a inovação se torna importante, uma vez que determinadas tecnologias são inovações. No contexto da Internet das Coisas e sustentabilidade, é fundamental explorar conceitos de inovação e como as empresas a percebem como vantagem estratégica para seus negócios.

\subsection{Sustentabilidade e ecoinovação}

A Conferência das Nações Unidas sobre o Ambiente e Desenvolvimento (Eco-92) tratou as questões humanas, econômicas e sociais, definindo metas de comprometimento no controle e redução de gases estufa para vários países, como $\mathrm{CO}_{2}$, maior responsável pelo aquecimento global. (Nascimento, 2012; Barbieri, Vasconcelos, Andreassi, \& Vasconcelos 2010).

Em 1997, o trabalho de John Elkington fez com que o conceito de sustentabilidade fosse ampliado além do desenvolvimento sustentável. Elkington (1998) criou um modelo para definir sustentabilidade: o triple bottom line, no qual o autor descreve a integração de três aspectos, chamados e descritos como um tripé: econômico, social e ambiental (profit, people, planet), que, unidos, abrangem tudo o que se torna necessário para alcançar um desenvolvimento sustentável.

Tal teoria defende que os aspectos econômicos não são suficientes para a sustentabilidade global de uma organização, são apenas de curto prazo. Assim, é preciso alinhar os aspectos econômicos ao contexto social e ambiental no qual a 
organização está inserida para que se atinja a sustentabilidade a longo prazo. O triple bottom line requer um sistema interligado, que atenda às necessidades de longo e curto prazo (Evangelista, 2010; Barbieri et al., 2010).

A ecoinovação diz respeito à criação de novos e competitivos esforços de produtos, processos, sistemas, serviços e procedimentos concebidos para satisfazer as necessidades humanas e proporcionar melhor qualidade de vida para todos, com utilização mínima do ciclo de vida de recursos naturais e liberação mínima de substâncias tóxicas. Inovações voltadas para a sustentabilidade passaram a ser denominadas no meio científico internacional como ecoinovações ou inovações ecológicas (ecoinnovations), inovações ambientais (environmental innovations), inovações sustentáveis (sustainable innovations) ou inovações verdes (green innovations) (Barbieri et al., 2010).

Oltra e Saint Jean (2009) observaram que as inovações ambientais apresentam processos, práticas, sistemas e produtos modificados ou novos criados com intuito de beneficiar o meio ambiente, contribuindo, assim, para sustentabilidade. A Internet das Coisas, portanto, tem forte associação à ecoinovação, porque pode ser um instrumento de inovação tecnológica capaz de gerar inovações que contribuem para a melhoria da sustentabilidade de maneira geral.

\subsection{Internet das coisas para melhoria do desempenho de sustentabilidade}

A Internet das Coisas não é resultante de uma nova tecnologia singular, mas de várias tecnologias que se complementam e proporcionam a diminuição da distância que separa o mundo físico e o virtual. Trata-se de um resultado do progresso tecnológico em campos paralelos e frequentemente sobrepostos, incluindo computação ubíqua, computação e telefonia móvel, telemetria, comunicação máquina-máquina, redes sem fio e redes de computação. A Internet das Coisas integra diferentes coisas para diferentes pessoas e tem potencial para mudar todos os aspectos da economia, sociedade, políticas e meio ambiente (Ashton, 2009; Galegale, Siqueira, Silva \& Souza, 2016).

Para Chase (2013), a Internet das Coisas cria uma inteligente e invisível rede que pode ser sentida, controlada e programada. Produtos baseados nessa 
tecnologia permitem a comunicação, diretamente ou indiretamente (com intermediários), entre si pela internet (Andersson \& Mattsson, 2015).

Além disso, a Internet das Coisas refere-se ao conceito de que internet não é apenas uma rede global para as pessoas se comunicarem umas com as outras pelos computadores, mas também uma plataforma em que dispositivos se comunicam eletronicamente com o mundo ao redor deles. É uma revolução que se torna possível a partir da combinação de tecnologias, sensores, processadores, computação em nuvem, conectividade sem fio (Zuin \& Zuin, 2016).

A Internet das Coisas também pode ser definida como coisas que possuem identidade própria e personalidade virtual, operando em espaços inteligentes e utilizando interfaces inteligentes, que se conectam e se comunicam por meio da tecnologia, integrando a sociedade e o ambiente em diferentes contextos (Kuo-Hui, Chunhua, Kim-Kwang Raymond \& Wayne, 2017).

Para Paes (2014), a Internet das Coisas está relacionada a todos os assuntos da comunicação e da troca das informações dos sistemas no ambiente por meio da tecnologia móvel. Ela representa a dinâmica que envolve a colaboração e a integração no ambiente digital, utilizada pelas soluções sistêmicas em diversos setores, de forma cada vez mais intensa, o que caracteriza o aspecto híbrido, multidisciplinar e interdisciplinar no processo de inovação tecnológica.

Diante do crescente acesso à internet e de tecnologias cada vez mais inovadoras, surge o desafio de como as organizações se posicionarão frente a tais mudanças: como organizações forçadas à mudança ou organizações pioneiras na inovação. É indiscutível que mudanças forçam adequação das organizações (Waring \& Tremblay, 2016; Maçaneiro \& Cunha, 2015).

Analisando a tipologia de rede que a Internet das Coisas pode usar para conectar aparelhos e pessoas, é possível associá-la a uma vasta gama de aplicações. No entanto, ainda há alguns obstáculos para seu desenvolvimento: asseguramento da privacidade, desenvolvimento de habilidades necessárias para alavancar a Internet das Coisas, gestão de crescente volume de dados e sensores inseguros (Fell, 2014).

Vermesan e Friess (2013) destacam sensores ambientais de poluição, gestão da água, iluminação pública, sensores de energia, mobilidade e saúde como aplicações da Internet das Coisas no contexto da sustentabilidade. Os autores 
corroboram afirmando que a Internet das Coisas tem valores que podem contribuir para a sustentabilidade.

A Internet das Coisas pode gerar valor e contribuir com aspectos do desenvolvimento sustentável em várias áreas, a saber: aviação comercial: melhora o planejamento de voos e na operação (economia de combustível); transporte ferroviário: redução nos custos de manutenção com a aplicação de diagnósticos em tempo real e análises preditivas, de forma a eliminar o desperdício em escalas na instrumentalização das frotas (economia no aumento da eficiência nos sistemas); energia: melhora a geração de energia a gás pela integração de gás natural e rede elétrica (economia em geração eficiente); saúde: identificação de desafios e melhoria em pesquisa, de forma a reduzir os custos de operações clínicas (Galegale et al., 2016; Vermesan \& Friess, 2013).

\section{Metodologia}

Esta pesquisa caracterizou-se por um estudo de caso no qual se buscou, a partir de uma investigação empírica, descobrir um fenômeno contemporâneo dentro de seu contexto da vida real, sendo fundamental, especialmente, quando os limites entre o fenômeno e o contexto não estão claramente definidos, e há necessidade de aprofundamento. $\mathrm{O}$ estudo de caso como estratégia de pesquisa compreende um método que abrange tudo - com a lógica de planejamento incorporando abordagens específicas à coleta de dados e à análise dos dados (Yin, 2015).

Quanto à abordagem, esta pesquisa é qualitativa, e quanto à natureza, exploratória, pois, conforme Fonseca (2002), a pesquisa qualitativa se preocupa com aspectos da realidade que não podem ser quantificados, concentrando-se na compreensão e explicação da dinâmica das relações sociais.

Para atender ao objetivo geral e aos específicos propostos inicialmente, foi necessário estruturar um instrumento de coleta de dados (questionário) com base na bibliografia, que respaldou as entrevistas dos sujeitos de pesquisa (no caso: gestores-chave) para a construção de relações teóricas (Eisenhardt \& Graebner, 2007).

A pesquisa buscou verificar os seguintes objetivos específicos: (I) identificar os fatores que influenciam a empresa a adotar inovações; (II) identificar como a 
tecnologia baseada na Internet das Coisas pode auxiliar ações mais sustentáveis na empresa; e (III) verificar a importância da inovação tecnológica e o conhecimento sobre a tecnologia da Internet das Coisas de gestores da empresa.

As perguntas para a entrevista foram elaboradas com base nos Fatores influenciadores na adoção de inovação nas empresas (Tabela 3), Características de inovação nas empresas (Tabela 4), e na pesquisa de Nemoto (2009).

\section{Tabela 3}

Inclusão de perguntas com base nos fatores influenciadores na adoção de inovação

\begin{tabular}{|c|c|}
\hline Fatores influenciadores & Questões \\
\hline $\begin{array}{l}\text { Hierarquia de autoridade - participação na tomada de } \\
\text { decisão de inovação. }\end{array}$ & \multirow{4}{*}{$\begin{array}{l}\text { A cultura de tomada de decisão para a } \\
\text { inovação na Klabin é mais centralizada } \\
\text { ou participativa? } \\
\text { A alta administração participa e apoia } \\
\text { a adoção de inovações que visam à } \\
\text { melhoria de desempenho de } \\
\text { sustentabilidade na empresa? }\end{array}$} \\
\hline $\begin{array}{l}\text { Influência do gestor na tomada da decisão de adoção } \\
\text { da inovação. }\end{array}$ & \\
\hline $\begin{array}{l}\text { A tomada de decisão pode ser dificultada, se a } \\
\text { empresa apresentar estrutura centralizada. }\end{array}$ & \\
\hline $\begin{array}{l}\text { A cultura pode favorecer ou dificultar a adoção da } \\
\text { inovação, dependendo da experiência do indivíduo. }\end{array}$ & \\
\hline Conhecimento para utilização da nova tecnologia. & \multirow{3}{*}{$\begin{array}{l}\text { A Klabin participa de redes de } \\
\text { inovação para o desenvolvimento e } \\
\text { adoção de inovação tecnológica? }\end{array}$} \\
\hline $\begin{array}{l}\text { O "compartilhamento" do conhecimento entre os } \\
\text { indivíduos favorece a inovação. }\end{array}$ & \\
\hline $\begin{array}{l}\text { Critérios utilizados pelos gestores para alocação de } \\
\text { recursos para projetos de inovação tecnológica. }\end{array}$ & \\
\hline $\begin{array}{l}\text { Liderança: desenvolvimento de novos produtos é o } \\
\text { principal objetivo da companhia na busca por novos } \\
\text { mercados. }\end{array}$ & \multirow[t]{2}{*}{$\begin{array}{l}\text { Os clientes e/ou fornecedores } \\
\text { influenciam a adoção de inovações } \\
\text { voltadas à melhoria de desempenho } \\
\text { de sustentabilidade? }\end{array}$} \\
\hline $\begin{array}{l}\text { Direcionador de resultado: a companhia objetiva lucrar } \\
\text { com base na inovação. }\end{array}$ & \\
\hline
\end{tabular}

Fonte: Elaboração própria.

\section{Tabela 4}

Inclusão de perguntas com base nas características de inovação nas empresas

\begin{tabular}{l|l}
\multicolumn{1}{c|}{ Característica e definição } & \multicolumn{1}{c}{ Questões } \\
\hline $\begin{array}{l}\text { Orientação externa e transparência em processos de inovação: } \\
\text { a companhia foca em diferenciação e competitividade junto a } \\
\text { outras organizações. }\end{array}$ & $\begin{array}{l}\text { De que forma a companhia diferencia-se } \\
\text { diz respeito à inovação? }\end{array}$ \\
& $\begin{array}{l}\text { Empresas que adotam inovações voltadas } \\
\text { à sustentabilidade influenciam a adoção } \\
\text { por parte da empresa? }\end{array}$ \\
\hline
\end{tabular}

(continua) 
(conclusão)

Qual (is) o (s) departamento (s) responsável (is) pela decisão de adoção de inovações tecnológicas na empresa?

Cooperação entre departamentos: a companhia promove sinergia e facilita a comunicação entre diferentes departamentos.

Como cada departamento participa do processo de adoção de inovação?

Como a Klabin promove sinergia na comunicação para a inovação entre os departamentos?

Aprendizagem e adaptação: a companhia procura entender o ambiente de competitividade de outras organizações e se adapta às realidades observadas.

Autonomia e possibilidade de experimentação: a companhia objetiva prestar atenção à busca de novas tecnologias, sendo ela a primeira a criar novos produtos ou melhorias em processos.

Fonte: Elaboração própria.
A companhia se adapta a partir de realidades ambientais observadas em outras organizações concorrentes ou é pioneira na adoção de inovações?

A existência de leis governamentais influencia a adoção de novas tecnologias para melhoria de desempenho de sustentabilidade?

Às questões também foi incorporada uma tabela com base na pesquisa de Nemoto (2009), na qual o entrevistado deve avaliar, em ordem crescente de importância, os fatores que motivam a empresa a adotar novas tecnologias. São eles: concorrência, melhoria na qualidade, exigência por parte de clientes, melhoria no desempenho de sustentabilidade, pioneirismo na adoção e cultura inovadora.

Por fim, além de verificar a importância dada à inovação na Klabin, verificouse o conhecimento dos gestores sobre a tecnologia da Internet das Coisas em relação a sua aplicação para a melhoria de desempenho de sustentabilidade, bem como sua percepção em relação ao uso dessa tecnologia pelos seus players.

Conforme informações obtidas pela Klabin S.A. (2016), a empresa, Klabin S.A., ou apenas Klabin, sediada em São Paulo - SP, caracterizada como "B2B" por comercializar exclusivamente com outras empresas, é a maior produtora e exportadora de papéis do Brasil. A companhia, líder na produção de papéis e cartões para embalagens, embalagens de papelão ondulado e sacos industriais, além de comercializar madeira em tora, é a única empresa no país a fornecer simultaneamente ao mercado: celulose de fibra curta (eucalipto) e fibra longa (pinus) e celulose fluff. A empresa foi fundada em 1899 e possui 18 unidades industriais no Brasil e uma na Argentina. 
Atualmente, a companhia está dividida em quatro unidades de negócio: florestal (matéria-prima para produção de celulose e comercialização de toras de madeira para serrarias e laminadoras), celulose (celulose de fibra curta, celulose de fibra longa e celulose fluff), papéis (papel kraft, papel cartão e papel reciclado) e conversão (embalagens de papelão ondulado e sacos industriais).

\section{Análise dos Resultados}

Foram entrevistados gestores, cujos nomes serão mantidos em sigilo, de três áreas da Klabin relacionadas ao tema do trabalho: (I) gestão de sustentabilidade, (II) gestão de pesquisa e desenvolvimento (P\&D) e (III) gestão de tecnologia da informação (TI). A área de sustentabilidade responde à diretoria de planejamento comercial, a área de P\&D responde à diretoria de projetos e tecnologia industrial, enquanto a área de TI responde à diretoria florestal.

As entrevistas, presenciais, aconteceram no escritório sede da Klabin S.A., em São Paulo - SP, entre os dias 31 de outubro de 2016 e 09 de novembro de 2016, e tiveram duração média de 35 minutos. Entrevistas-piloto foram realizadas previamente com analistas das áreas para adaptação e verificação do questionário.

Ambos os gestores têm pós-graduação e experiência na área em que atuam. O número de subordinados é maior em TI (109), seguido por P\&D (90) e sustentabilidade (2).

\subsection{Fatores que influenciam a empresa a adotar inovações}

Para atender ao primeiro objetivo específico, a entrevista foi conduzida de forma a receber dos participantes da pesquisa informações pertinentes ao tema.

Os gestores receberam uma estrutura, conforme modelo da Tabela 5, na qual, por meio de uma escala numérica de 1 a 6 , o gestor atribuía, em ordem crescente, o grau de importância dado a um fator que possivelmente motiva a Klabin a adotar novas tecnologias.

Os resultados mostram a atribuição do nível de importância por gestor em cada uma das áreas. Há uma similaridade na visão das áreas de sustentabilidade e TI sobre os aspectos de maior importância, exceto pelos dois últimos, pioneirismo na adoção e cultura inovadora, também vistos pela área de TI como os dois últimos fatores influenciadores (cf. Tabela 5). Pode-se dizer, portanto, que os 4 principais 
fatores influenciadores na adoção de novas tecnologias para os gestores entrevistados na Klabin são: exigência por parte de clientes, concorrência, melhoria na qualidade e melhoria no desempenho de sustentabilidade.

\section{Tabela 5}

Fatores influenciadores na adoção de novas tecnologias para cada área

\begin{tabular}{|c|c|c|}
\hline Sustentabilidade & P\&D & TI \\
\hline $\begin{array}{l}\text { Exigência por parte } \mathrm{de} \\
\text { clientes. }\end{array}$ & Exigência por parte de clientes. & $\begin{array}{l}\text { Melhoria no desempenho de } \\
\text { sustentabilidade. }\end{array}$ \\
\hline Concorrência. & Concorrência. & Melhoria na qualidade. \\
\hline Melhoria na qualidade. & Melhoria na qualidade. & Exigência por parte de clientes. \\
\hline $\begin{array}{l}\text { Melhoria no desempenho de } \\
\text { sustentabilidade. }\end{array}$ & $\begin{array}{l}\text { Melhoria no desempenho de } \\
\text { sustentabilidade. }\end{array}$ & Concorrência. \\
\hline Pioneirismo na adoção. & Cultura inovadora. & Pioneirismo na adoção. \\
\hline Cultura inovadora. & Pioneirismo na adoção. & Cultura inovadora. \\
\hline
\end{tabular}

Fonte: Elaboração própria.

Atribuindo-se pesos de forma a identificar, em valor médio, quais os quatro fatores em ordem de importância geral, verificou-se que, na Klabin, os fatores que influenciam a adoção de novas tecnologias, em ordem de importância, são: (1) exigência por parte de clientes, (2) concorrência, (3) melhoria na qualidade e (4) melhoria no desempenho de sustentabilidade.

Quando questionados sobre qual(is) é(são) o(s) departamento(s) responsável(eis) pela adoção de inovações tecnológicas na Klabin, os três gestores responderam que a área de P\&D tem um papel mais importante e estratégico no assunto. Para a área de TI, não existe apenas um departamento que concentra o processo de inovações tecnológicas. Para P\&D, está acontecendo um processo de aprendizagem, pois existem comitês de P\&D (diretor, gerencial e geral) que dependem do valor atribuído aos projetos. Para sustentabilidade, a área de viabilidade econômica se estrutura com o desenho do investimento econômico necessário.

Ao serem questionados como cada departamento participa no processo de adoção de inovação, duas áreas identificaram que o processo parte de uma demanda e oportunidades de mercado (corroborando os fatores "exigência por parte de clientes" e "concorrência" discutidos acima). Para TI, existe, a partir de todas as áreas da companhia, busca por apoio de P\&D e TI. Para sustentabilidade, existe um departamento que sente a demanda, aciona P\&D e, juntos, trabalham para construir uma solução de inovação visando atender à necessidade do cliente, porém 
existem projetos mais simples que não necessitam de áreas de planejamento estratégico ou viabilidade econômica, apenas P\&D. Para projetos mais complexos, há uma gama de áreas que atuam. Alguns projetos são "top-down" a partir da diretoria, então as áreas se mobilizam para atender a esses projetos. P\&D descreveu que alguns projetos nascem em comitês, que se reúnem alinhados ao planejamento estratégico da Klabin, no qual os projetos são levados para aprovação.

Ao serem questionados como a Klabin promove sinergia na comunicação para a inovação entre os departamentos, ambas as áreas citaram a existência dos comitês, nos quais são compartilhadas, nos níveis gerencial e operacional, as iniciativas em andamento.

Perguntados se, por conta da existência dos comitês ou de algum outro fator, a cultura de tomada de decisão para adoção de inovação na Klabin é mais centralizada ou participativa, observou-se que, para a sustentabilidade, é mais centralizada, mesmo havendo exemplos nas duas frentes. Para TI, observou-se que há um equilíbrio, e, para $\mathbf{P \& D}$, é um aprendizado, uma cultura de mudança, que não pode ser "top-down", e que, em alguns momentos, é necessário convencer a diretoria. Desse modo, não é possível responder se é mais centralizada ou participativa.

A companhia se adapta a partir de realidades ambientais observadas em outras organizações ou é pioneira na adoção de inovações? TI considera que, pela característica no negócio da Klabin (indústria de manufatura tradicional e de capital intensivo), a empresa é pioneira em muitas coisas. Sustentabilidade e P\&D veem a Klabin como "fast-follower". Para P\&D, é raro haver um "break-through" no setor de papel e celulose; a Klabin não é antecipativa, é reativa. Sustentabilidade, no entanto, vê exemplos pontuais de projetos inovadores que surgiram como iniciativa própria, ainda que possam ter sofrido influências de mercado.

Quando questionados de que forma a companhia se diferencia em relação a outras organizações no que diz respeito à inovação, TI considera que a Klabin trata a inovação dentro do contexto do negócio e busca estar aberta para novas oportunidades. Sustentabilidade vê diferenciações principalmente em energias renováveis. P\&D não enxerga diferenciação por parte da Klabin, pois vê empresas concorrentes que têm equipes específicas dedicadas exclusivamente à pesquisa, mas considera que a Klabin está entrando num círculo das empresas inovadoras do setor e irá se inserir quando a construção do centro de inovação for concluída. 
Os gerentes também foram questionados se clientes e/ou fornecedores influenciam a adoção de inovações voltadas à melhoria de sustentabilidade. TI vê tanto clientes quanto fornecedores como influenciadores. Sustentabilidade e P\&D veem clientes como principais motivadores de projetos ou processos de inovação. Tais afirmações também corroboram a atribuição dos gestores de que "exigência por parte de clientes" é o principal fator que motiva a adoção de novas tecnologias por parte da Klabin. No entanto, P\&D diz que toma cuidado em relação aos pedidos dos clientes, porque não pode fazer exatamente o que eles pedem, mas que é preciso olhar as oportunidades e saber ouvi-los.

Quando questionados se as empresas que adotam inovações voltadas para a sustentabilidade influenciam a adoção por parte da Klabin, verificou-se que, para $\mathrm{TI}$, a Klabin vem sempre buscando as melhores práticas de sustentabilidade há mais de 70 anos, sendo essa característica presente no DNA da companhia. Sustentabilidade considera que elas provocam um processo mínimo de mudança internamente. P\&D fez uso da TetraPak como exemplo, por ser a maior cliente da Klabin, na qual a empresa influencia totalmente.

Quando perguntados como a inovação tecnológica pode auxiliar a melhoria do desempenho de sustentabilidade na Klabin, os gestores responderam desta forma:

[...] uma tecnologia na qual caminhões que transportam madeira podem trafegar em comunidades sem levantar poeira (Gestor da Área de TI, grifo nosso, 2016).

[...] pensar no "payback" do investimento, pois é um equilíbrio delicado; se a Klabin começar a automatizar demais a produção, alterará a dinâmica social, quando se pensa em empregos desnecessários a partir da tecnologia; o Projeto Puma é um grande exemplo, pois resíduos produtivos estão sendo transformados em outros produtos economicamente interessantes para a companhia (Gestor da Área de Sustentabilidade, grifo nosso, 2016).

[...] melhorar um digestor de forma a economizar madeira, utilizar menos produtos químicos e diminuir a gramatura do papel (Gestor da Área de P\&D, grifo nosso, 2016).

Quando perguntados se a alta administração participa e apoia a adoção de inovações que visam à melhoria do desempenho de sustentabilidade, para TI, a alta administração tem a preocupação, porém não deixou claro de que forma ela 
acontece, apenas exemplificou que, na execução do Projeto Puma, a Klabin fez parcerias com as prefeituras para dividir 0 imposto de renda gerado. Sustentabilidade optou por não responder à pergunta. P\&D também não respondeu à pergunta.

Quando questionados sobre se a existência de leis governamentais influencia a adoção de novas tecnologias para a melhoria do desempenho de sustentabilidade, TI apenas respondeu "sim" e que a Klabin articula parceiros na esfera pública. Sustentabilidade também disse que sim, além de que as áreas florestais preservadas pela companhia são superiores às exigências legais. $A$ área de P\&D considera, por um lado, que o INPI (Instituto Nacional de Propriedade Industrial) possui um processo moroso para conceder uma patente, mas, por outro lado, existem leis que incentivam a fazer P\&D, pois oferecem beneficiamento em impostos retroativos.

Ao serem questionados se a Klabin participa de redes de inovação para o desenvolvimento e adoção de inovações tecnológicas e como se dá a troca de informações, TI disse que sim, citando alguns grupos. Sustentabilidade não citou nenhum grupo especificamente, porém acredita que unidades da Klabin participem e citou um grupo de estudos em sustentabilidade como rede de inovação. P\&D disse que a Klabin participa em muitas redes por meio de fóruns de discussão com empresas, universidades e institutos de pesquisa.

De maneira geral, é possível verificar que não são muitos os fatores que influenciam a Klabin a adotar novas tecnologias, porém cada um possui seu grau de importância, dependendo do momento econômico da companhia, que é influenciado principalmente pelos maiores clientes. Nesse sentido, o principal fator observado é a exigência por parte de clientes em relação a demandas e oportunidades de mercado. Empresas concorrentes influenciam em uma escala média, quando a adoção diz respeito à sustentabilidade.

Leis governamentais foram consideradas importantes, não a ponto de influenciarem a adoção de tecnologias para melhorar 0 desempenho de sustentabilidade. Não foi respondido pelos entrevistados se a alta administração participa do apoio e da adoção de inovações que visam à melhoria do desempenho de sustentabilidade. Entretanto, entende-se, pela omissão e pelo pouco engajamento da alta administração, que há uma baixa participação, em virtude da existência de comitês que precisam defender projetos de inovação para os diretores. 
A concorrência e a melhoria na qualidade também foram citadas como influenciadores. A cultura de tomada de decisão da Klabin é mais centralizadora, mostrando que, conforme Donaldson (1998), a companhia está inserida num ambiente mais estável, o setor de papel e celulose, e, ainda para o autor, não necessitando de altas inovações para sobreviver. A busca pela inovação na companhia ocorre dentro de seus limites, como visto na exemplificação da existência dos comitês de P\&D, corroborando pesquisas que vêm sendo desenvolvidas pela IBM, que afirmam que as principais fontes de inovação nas empresas são internas.

\subsection{A tecnologia baseada na internet das coisas no auxílio de ações mais sustentáveis na empresa}

A pesquisa evidenciou que são três os conceitos que embasam a tecnologia da Internet das Coisas: (I) sensores e atuadores - objetos os usam para interagirem com o ambiente na captação e troca de informações; (II) processos incorporados processos que dão inteligência aos objetos; e (III) conectividade e computação em nuvem - tecnologias de comunicação que funcionam em rede e integram as coisas.

Ao analisar o presente estudo, percebe-se que a Internet das Coisas tem inúmeras aplicações nos mais variados campos, sendo a sustentabilidade um deles. A tecnologia, entretanto, por mais que seja voltada para melhorar processos de agricultura, por exemplo, pode estar associada à sustentabilidade no que diz respeito ao bom uso do solo e à gestão da água. Em outras palavras, por mais que o dispositivo inventado, que funciona integrado a um sistema que tem como base a Internet das Coisas, não esteja diretamente voltado para a contemplação de aspectos ambientais, sociais e econômicos (sustentabilidade) de uma única vez, suas implicações podem gerar melhorias parciais e que, no fim, contribuem da mesma forma para o desenvolvimento sustentável, apresentando melhorias no meio ambiente, na vida das pessoas, ou até mesmo em ganhos econômicos para pequenas comunidades.

As melhorias que a Internet das Coisas é capaz de gerar no campo da sustentabilidade podem ser várias, como mostradas no estudo de Cognizant (2014): melhoria da qualidade do ar; gestão eficiente da água; melhoria dos índices de trânsito em centros urbanos, reduzindo estresse dos indivíduos; carros mais eficientes e que consumam menos combustível; aparelhos capazes de aumentar a 
longevidade das pessoas; pontes e sistemas integrados de infraestrutura de transporte capazes de estarem mais atentos ao próprio desgaste; sistemas eficientes de coleta de lixo; gestão de economia de energia; incentivos tecnológicos na agricultura, gerando renda e produções mais limpas e sustentáveis; estímulos ao uso de energias mais limpas, barateando seu custo e aumentando sua eficiência operacional; irrigadores inteligentes, que economizam água e poupam recursos; controles automatizados nas residências, que economizam energia; rede de transportes inteligente, que facilite a vida das pessoas; manufatura; supply-chain; agricultura; óleo e gás; entre muitos outros. Todas as tecnologias listadas impactam positivamente, de alguma forma, um ou mais dos tripés da sustentabilidade descritos na pesquisa, sendo eles ambiental, econômico e social.

No contexto organizacional, os gestores indicaram que isso não é diferente, a Internet das Coisas, como nos vários exemplos citados acima, é capaz de estar presente dentro das organizações, que podem ser vistas como pequenas casas ou pequenas fazendas, integrando a tecnologia e proporcionando sistemas mais inteligentes e que fazem, ao mesmo tempo, melhor uso de recursos ambientais e melhoram a qualidade de vida dos funcionários, seja um sistema eficiente de energia, gestão da água, iluminação, janelas que acompanham o movimento do sol para poupar recursos naturais, seja em ambientes mais ergonômicos ou aplicativos que lembram os funcionários de lavarem suas mãos ou se hidratarem com frequência e que, ao mesmo tempo, monitoram os índices e a rotina das pessoas, gerando informações médicas que podem auxiliar a prevenção de doenças.

No caso da Klabin, várias tecnologias da Internet das Coisas exemplificadas acima são interessantes para as atividades da companhia e o setor de atuação: um manejo florestal sustentável, processos produtivos mais limpos e eficientes e entrega eficaz.

Quando questionados sobre como inovações tecnológicas poderiam auxiliar a melhoria do desempenho de sustentabilidade na Klabin, os gestores deram exemplos de melhoramento de digestores, processos produtivos que aproveitam melhor os resíduos e caminhões capazes de trafegar sem levantar poeira. Todas essas ideias, dadas pelos gestores, agregadas às tecnologias que descrevem a Internet das Coisas, podem ser capazes de auxiliar ações mais sustentáveis na empresa. No futuro, se perguntados novamente quais fatores influenciam a Klabin a 
adotar novas tecnologias, possivelmente "melhoria no desempenho de sustentabilidade" terá maior destaque.

\subsection{A importância da inovação tecnológica e o conhecimento de gestores da empresa sobre a tecnologia da internet das coisas}

A gerência de P\&D nunca havia ouvido falar sobre Internet das Coisas. Simultaneamente, as gerências de sustentabilidade e TI já haviam ouvido falar sobre o tema. A gerência de TI exemplificou casos nos quais dados sobre produção são capturados nas fábricas e enviados para um sistema de armazenamento em nuvem chamado "Brain Cube", que devolve com informações dos ajustes necessários a serem feitos para melhorar 0 desempenho das fábricas. A gestão de sustentabilidade, por sua vez, exemplificou máquinas capazes de mensurar, com maior precisão, o consumo de energia, água, tempo de produção, e enviar essas informações para uma central, responsável pelo gerenciamento. A gerência de sustentabilidade também citou um possível sistema de monitoramento de animais nas florestas com o apoio de câmeras, que rastreiam e montam mapas de vivência desses animais, espécies, entre outros, além da atuação de dispositivos em outros indicadores de biodiversidade, como qualidade do ar, solo, água, taxa de crescimento de árvores, presença de pragas invasoras, os quais pudessem soar alarmes para auxiliar os responsáveis pela gestão das florestas.

Nesta pesquisa, portanto, foi possível entender a adoção da inovação tecnológica no auxílio da melhoria do desempenho de sustentabilidade na empresa Klabin S.A. de papel e celulose.

A Internet das Coisas é uma tecnologia estratégica no que diz respeito ao uso da inovação para se alcançar determinado fim. Nesse sentido, sua adoção tecnológica pode e poderá auxiliar a melhoria do desempenho de sustentabilidade na empresa Klabin. De maneira geral, é possível alcançar melhores índices de sustentabilidade com o uso de inovação e novas tecnologias emergentes (Timilsina, Kotani \& Kamijo, 2017).

Mesmo se colocando em uma posição de "fast-follower", a Klabin possui áreas e equipes dedicadas para discutir o tema em conjunto, assim como comitês de $P \& D$, estratégicos para a companhia no que diz respeito ao tema. Além disso, a 
Klabin é vista como uma das empresas mais sustentáveis do Brasil por sua presença do Índice de Sustentabilidade da BM\&F Bovespa, Guia Exame de Sustentabilidade, WWF Environmental Company Paper Index, Carbon Disclosure Project, certificação de manejo florestal responsável $\mathrm{FSC} \circledast$, entre os vários prêmios e destaques que a empresa já recebeu.

Neste estudo, utilizou-se do Software Sentiment Analyzer ${ }^{1}$, desenvolvido pelo pesquisador Daniel Soper, o qual permite desenvolver análise de sentimentos com base nas transcrições obtidas. O sistema calcula uma nota de sentimento que reflete o sentimento geral, o tom ou o sentimento emocional do seu texto de entrada. Os escores de sentimento variam de $-100 \mathrm{a}+100$, em que -100 indica um tom muito negativo ou grave $e+100$ indica um tom muito positivo ou entusiasmado.

Ao observar os objetivos específicos que nortearam a pesquisa, verificou-se o seguinte resultado (cf. Figura 1).

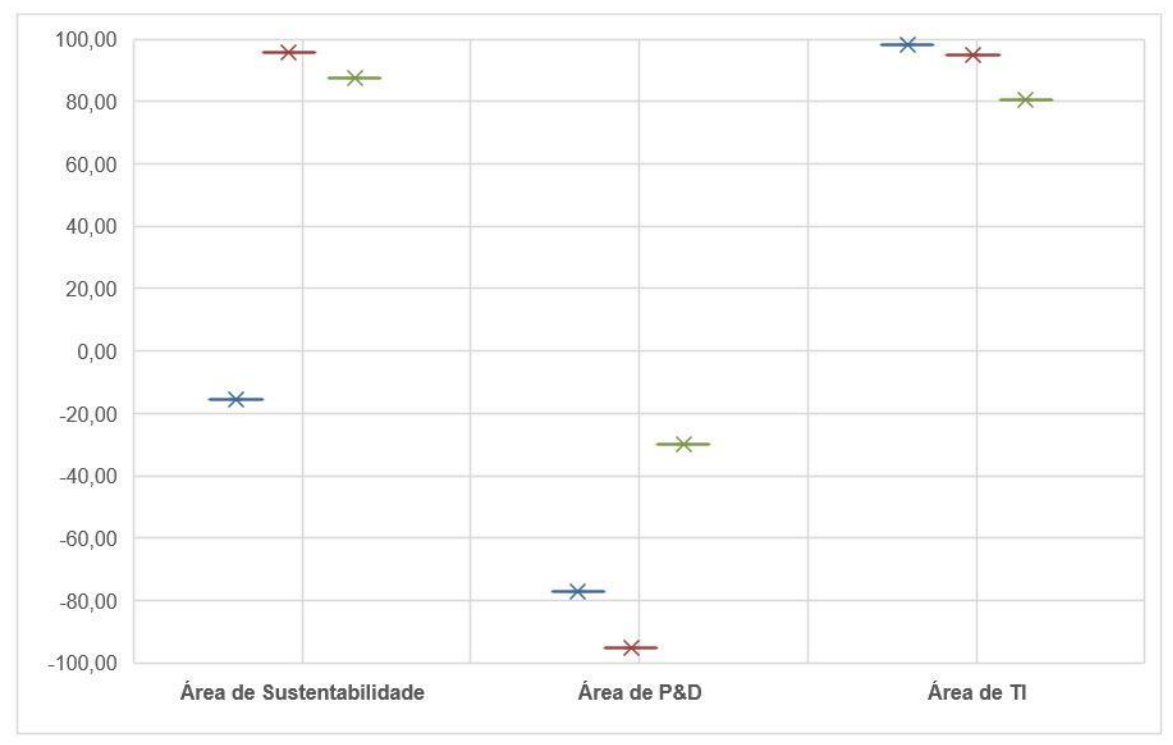

\section{Figura 1}

Análise de sentimentos.

Fonte: Elaboração própria.

Notas: "Azul": 1-Fatores que influenciam a empresa a adotar inovações; "Vermelho": 2-A tecnologia baseada na Internet das Coisas no auxílio de ações mais sustentáveis na empresa; e "Verde": 3-A importância da inovação tecnológica e o conhecimento sobre a tecnologia da Internet das Coisas de gestores da empresa.

Observando as dimensões que foram analisadas e que nortearam esta pesquisa, observou-se que a "área de $\mathrm{Tl}$ " demonstrou maior sentimento positivo $(1: 98 \%, 2: 95 \%$ e $3: 80,4 \%)$ em relação às respostas obtidas sobre todas as dimensões. Isso se deve ao fato de que a "área de Tl" reconhece que os

\footnotetext{
${ }^{1}$ Disponível em: http://www.danielsoper.com/sentimentanalysis/default.aspx Acesso: 10 de outubro de 2017.
} 
fornecedores colaboram com o processo de inovação de forma efetiva e que a tecnologia das Internet das Coisas pode trazer benefícios sustentáveis para a empresa.

De forma contrária, a "área de P\&D" foi a que obteve maior sentimento negativo em todas as dimensões (1:-77\%, 2:-95\% e 3:-29,8\%), indicando, em várias passagens das transcrições, desconhecimento da tecnologia Internet das Coisas e apoiando-se nas exigências do mercado para o desenvolvimento de novas estratégias de inovação na organização, o que torna necessário o incentivo para uma "cultura inovadora" que esteja alinhada com as tendências tecnológicas. No caso da "área de Sustentabilidade", foi possível perceber que apenas os "fatores que influenciam a empresa a adotar inovações" causam certa preocupação em relação às estratégias que são tomadas (1:-15,6\%, 2:95,8\% e 3:87,7\%), já que a área apresentou preocupações quando as visões entre áreas são distintas. O cliente, porém, foi considerado o principal "driver", pois exerce influência no processo de tomada de decisão na prestação de serviços, como, por exemplo:

Unilever exige que a gente faça tal projeto de melhoria, ou adoção de nova tecnologia, senão eles ameaçam diminuir o negócio com a gente ou nos penalizam de alguma maneira [...] (Gestor da Área de Sustentabilidade, Grifo Nosso, 2016).

Ao final da análise, utilizou-se do software NVivo 11Pro na busca por padrões comuns aos entrevistados. Nesse sentido, buscou-se comparar os resultados pelo coeficiente de correlação de Pearson ( $\rho$ ). Essa medida, segundo Cramer e Howitt (2004), avalia a intensidade da associação linear entre duas variáveis ( $x$ e y), a qual assume valores entre -1 e 1 (esta pesquisa obteve apenas valores na escala positiva). $O$ cálculo de $\rho$ de Pearson formaliza-se na seguinte equação:

$$
\rho=\frac{\sum_{i=1}^{n}\left(x_{i}-\bar{x}\right)\left(y_{i}-\bar{y}\right)}{\sqrt{\sum_{i=1}^{n}\left(x_{i}-\bar{x}\right)^{2}} \cdot \sqrt{\sum_{i=1}^{n}\left(y_{i}-\bar{y}\right)^{2}}}=\frac{\operatorname{cov}(X, Y)}{\sqrt{\operatorname{var}(X) \cdot \operatorname{var}(Y)}}
$$

As saídas da análise de clusters dos entrevistados (gestores) apresentadas na Figura 1 indicaram uma forte correspondência entre a "área de sustentabilidade" e a "área de P\&D" $(\rho=0,75)$, e uma correlação moderada entre a "área de TI" e "área de sustentabilidade" $(\rho=0,52)$ e "área de TI" e "área de P\&D". Isso demonstra que, nas diversas questões que nortearam esta pesquisa, as áreas de P\&D e Sustentabilidade apresentaram um alinhamento maior na exposição de seus 
discursos em relação ao apresentado pela área de TI, e que as áreas de TI e P\&D indicaram o maior distanciamento entre a similaridade semântica de frases obtidas $(\rho=0,42)$. Diante disso, observa-se que há maior necessidade que as áreas estejam alinhadas com as temáticas da área de TI. Também cabe reforçar que existem comitês responsáveis por discutir sustentabilidade na Klabin nos mais amplos contextos e que as áreas de "Sustentabilidade" e "P\&D", diferentemente da "área de Tl", ocupam cadeiras fixas nessas discussões. A "área de Tl", por sua vez, não integra os comitês, o que mostra um maior alinhamento entre "P\&D" e "Sustentabilidade".

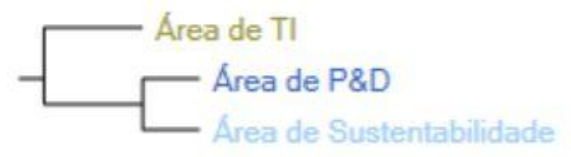

\section{Figura 2}

Mapa em cluster por similaridades entre os entrevistados Fonte: Elaboração própria.

\section{Conclusões e Recomendações Gerenciais}

De maneira geral, os resultados das entrevistas indicaram que: a) a alta administração pouco incentiva tecnologias que promovem a sustentabilidade, pois se considera que, se existissem exemplos concretos e consideráveis de inovações para a sustentabilidade, esses teriam sido comentados nas entrevistas; b) não há conhecimento por parte dos gestores da Klabin no que diz respeito à atuação dos concorrentes com o uso da Internet das Coisas ou inovações em tecnologias que promovem a sustentabilidade; c) o setor de papel e celulose força as empresas a serem mais reativas, pois se trata de um setor que não exige alto grau de inovação; há pouco conhecimento sobre a Internet das Coisas por parte dos gestores; d) a Klabin é uma empresa "fast-follower", que se posiciona como empresa que rapidamente se adapta a mudanças; a tomada de decisão na companhia é mais centralizada porque, mesmo considerando os vários comitês e comissões existentes na empresa, a alta administração sempre deverá ser convencida da importância de determinadas ideias; e, e) por fim, não foram encontradas altas taxas de inovação. É 
possível que a companhia inove em tecnologias para a sustentabilidade, pois dispõe de equipes e recursos necessários para tanto.

Unindo-se, portanto, os esforços da Klabin para se inserir e se manter nos índices de sustentabilidade mais importantes do Brasil e do mundo à diversificação nas discussões a respeito de inovação e tecnologia, com pautas voltadas para melhorias de sustentabilidade nos processos, não apenas nos produtos, com o do uso da tecnologia, a companhia será capaz de agregar altos ganhos competitivos no que diz respeito à inovação. É considerado, pelos gestores entrevistados, que o setor de papel e celulose pouco inova, porém, inovar em Internet das Coisas nas florestas, por meio de dispositivos mais eficientes, sistemas capazes de monitorar e rastrear atividades em tempo real, cadeia de suprimento e fornecimento mais inteligente, máquinas que podem gerar informações sobre gaps no processo produtivo (falhas no sistema, atrasos, defeitos, entre outros), entre vários aspectos discutidos nas entrevistas, pode aumentar a competitividade da companhia nessa área.

A área de sustentabilidade, por fim, mostrou-se mais propensa a novas ideias no que diz respeito a uma maior presença da Internet das Coisas na Klabin e a inovações tecnológicas capazes de melhorar o desempenho de sustentabilidade na empresa do que as outras áreas entrevistadas, o que se deve pelo fato de essa área ter uma ampla visão sobre como a tecnologia pode melhorar o desempenho da companhia. A área de TI também vê a tecnologia com alto grau de importância. A área de P\&D, por fim, a considera importante, porém, fortemente aposta na presença humana como facilitadora do controle da tecnologia, a partir de processos que não são totalmente automatizados.

\section{Referências}

Andersson, P., \& Mattsson, L. (2015). Service innovations enabled by the "internet of things". IMP Journal, 9(1), 85-106. doi:10.1108/IMP-01-2015-0002

Ashton, K. (2009). That 'Internet of Things' Thing. RFID Journal, New York. Disponível em: <http://www.rfidjournal.com/articles/view?4986>. 
Barbieri, J., Vasconcelos, I.; Andreassi, T.; Vasconcelos, F. (2010). Inovação e sustentabilidade: novos modelos e proposições. Revista de Administração de Empresas, 50(2), p. 146-154. DOI: 10.1590/S0034-75902010000200002.

Brooke, H. (2016). Inside the Digital Revolution. Journal of International Affairs, 1(10).

Chase, J. (2013). The Evolution of the Internet of Things. Texas Instruments, Dallas, p. 1-5. Disponível em: <http://www.ti.com/lit/ml/swrb028/swrb028.pdf

Cognizant (2014). Reaping the Benefits of the Internet of Things. Disponivel em: https://www.cognizant.com/InsightsWhitepapers/Reaping-the-Benefits-of-theInternet-of-Things.pdf

Cramer, D., \& Howitt, D. (2004). The Sage dictionary of statistics: a practical resource for students in the social sciences. London: Thousand Oaks: SAGE Publications.

Damanpour, F., Schneider, M. (2006). Phases of the adoption of innovation in organizations: effects of environment. organization and top managers. British Journal of Management, 3(17), 215-236.

Donaldson, L. (1988). The contingency theory of organzations. Foundation for Organization Science - SAGE.

Egeraat, C., Kogler, D. (2013). Global and regional dynamics in knowledge flows and innovation networks. European Planning Studies, 9(21), 1317-1322. DOI: $10.1080 / 09654313$

Eisenhardt, K., Graebner, M. (2007). Theory building from cases: opportunities and challenges. Academy of Management Journal, 50( 1), p. 25-32.

Elkington, J. (1998). Partnerships from Cannibals with Folks: The Triple Bottom Line of 21-st Century Business. Environmental Quality Management, Cincinnati, p. 3751.

Evangelista, R. (2010). Sustentabilidade: um possível caminho para o sucesso empresarial? Revista Portuguesa e Brasileira de Gestão, Lisboa, 9(1-2).

Fell, M. (2014). Roadmap for the Emerging "Internet of Things". Carré \& Strauss: Londres.

Fonseca, J. J. S. da. (2002). Metodologia da pesquisa científica. Ceará: Universidade Estadual do Ceará.

Galegale, G., Siqueira, E., Silva, C., Souza, C. (2016). Internet das Coisas aplicada a negócios: um estudo bibliométrico. JISTEM J.Inf.Syst. Technol. Manag., São Paulo, v. 13(3), 423-438. DOI: 10.4301/s1807-17752016000300004

Klabin. (2015). Relatório de Sustentabilidade. Disponível em: http://rs.klabin.com.br/ 
Klabin. (2016). Site corporativo. Disponível em: https://www.klabin.com.br/pt/home/

Kuo-Hui, Y., Chunhua, S., Kim-Kwang Raymond, C., \& Wayne, C. (2017). A Novel Certificateless Signature Scheme for Smart Objects in the Internet-of-Things. Sensors (14248220), 17(5), 1-17. doi:10.3390/s17051001

Lencioni, S. (2015). Região Metropolitana de São Paulo como centro da inovação do Brasil. Cad. Metrop., 17(34), 317-328. DOI: 10.1590/2236-9996.2015-3401

Lindqvist, U., Neumann, P. (2017). The future of the Internet of Things. Communications of the ACM, 2(60). DOI: $10.1145 / 3029589$

Maçaneiro, M., Cunha, S. (2015). Relações entre fatores contextuais internos às organizações e a adoção de estratégias proativas de ecoinovações. Revista de Administração do Mackenzie, 3(16), 20-50. ISSN 1578-6971

Martins, V. (2015). Gestão da inovação em empresas que adotam diferentes processos de tomada de decisão. Revista Gestão \& Tecnologia, 15(3), 211-244. e-ISSN: 2177-6652

Nascimento, E. (2012). Trajetória da sustentabilidade: do ambiental ao social, do social ao econômico. Estudos Avançados, 26. Disponível em: http://www.scielo.br/pdf/ea/v26n74/a05v26n74.pdf. Acesso em: 10 out. 2016.

Nemoto, M. (2009). Inovação Tecnológica: Um estudo exploratório de adoção do RFID (identificação por radiofrequência) e redes de inovação internacional. (Tese de Doutorado em Administração. Universidade de São Paulo, São Paulo, SP, Brasil).

Neto, C., Longo, R. (2001). A gestão do conhecimento e a inovação tecnológica. Transinformação, 13(2), 93-110. DOI: 10.1590/S0103-37862001000200007

Oltra, V., Saint Jean, M. (2005). The dynamics of environmental innovations: three stylised trajectories of clean technology. Economical Innovation and New Technology, 14(3), 189-212.

Paes, W. (2014). Interoperabilidade móvel: A Internet das Coisas. Revista de Universidade Vale do Rio Verde, Três Corações, 1(12), p. 794-810.

Raeder, S. (2016). Geografia e inovação tecnológica. Mercator (Fortaleza), 15(2), 77-90. DOI: 10.4215/RM2016.1502.0005

Rosa, L., Kneipp, J., Bichueti, R., Gomes, C., Zamberlan, J. (2013). The Innovation Process and the Development of a Sustainability Strategy. Latin American Business Review, p. 289-308. 
Souza, J., Bruno-Faria, M. (2013). Processo de inovação no contexto organizacional: uma análise de facilitadores e dificuldades. Brazilian Business Review, 3(10), 113136. ISSN 1807-734X

Timilsina, R., Kotani, K., Kamijo, Y. (2017). Sustainability of common pool resources. Plos One Tianjin University of Technology, 12(10). DOI: 10.1371/journal.pone.0170981

Vermesan, O., Friess, P. (2013). Internet of Things: Covering Technologies for Smart Environments and Integrated Ecosystems. Aalborg: River Publishers.

Waring, T., Tremblay, E. (2016). An evolucionary approach to sustainability science. Cliodynamics The Journal of Quantitative History and Cultral Evolution, 7(1), 119167. DOI: $10.21237 /$ C7clio7131139

Yin, R. (2015). Estudo de Caso: Planejamento e Métodos. Bookman: Porto Alegre.

Zuin, V., Zuin, A. (2016). A formação no tempo e no espaço da Internet das Coisas. Educ. Soc., Campinas, 37(136), 757-773. DOI: 10.1590/es0101-73302016167198 